\title{
Therapeutic Activity of Type 3 Streptococcus pneumoniae Capsule Degrading Enzyme Pn3Pase
}

\author{
Amy V. Paschall ${ }^{1,2}$ • Dustin R. Middleton 1,2 • Paeton L. Wantuch 1,2 • Fikri Y. Avci ${ }^{1,2}$
}

Received: 18 September 2020 / Accepted: 19 October 2020 / Published online: 2 November 2020

(C) Springer Science+Business Media, LLC, part of Springer Nature 2020

\section{ABSTRACT}

Purpose Streptococcus pneumoniae (Spn) serotype 3 (Spn3) is considered one of the most virulent serotypes with resistance to conventional vaccine and treatment regimens. Pn3Pase is a glycoside hydrolase that we have previously shown to be highly effective in degrading the capsular polysaccharide of type 3 Spn, sensitizing it to host immune clearance. To begin assessing the value and safety of this enzyme for future clinical studies, we investigated the effects of high doses of Pn3Pase on host cells and immune system.

Methods We assessed the enzyme's catalytic activity following administration in mice, and performed septic infection models to determine if prior administration of the enzyme inhibited repeat treatments of Spn3-challenged mice. We assessed immune populations in mouse tissues following administration of the enzyme, and tested Pn3Pase toxicity on other mammalian cell types in vitro.

Results Repeated administration of the enzyme in vivo does not prevent efficacy of the enzyme in promoting bacterial clearance following bacterial challenge, with insignificant antibody response generated against the enzyme. Immune homeostasis is maintained following high-dose treatment with Pn3Pase, and no cytotoxic effects were observed against mammalian cells.

Conclusions These data indicate that Pn3Pase has potential as a therapy against Spn3. Further development as a drug product could overcome a great hurdle of pneumococcal infections.

\section{Fikri Y. Avci}

avci@uga.edu

Department of Biochemistry \& Molecular Biology, University of Georgia, Athens, Georgia 30602, USA

2 Center for Molecular Medicine, University of Georgia, Athens, Georgia 30602, USA
KEY WORDS capsular polysaccharide · carbohydrate-active enzyme · enzyme therapy · glycoside hydrolase · Streptococcus pneumoniae

$\begin{array}{ll}\text { ABBREVIATIONS } \\ \text { AV } & \text { Annexin V } \\ \text { BAL } & \text { Broncheal alveolar lavage } \\ \text { CFU } & \text { Colony forming units } \\ \text { CHO } & \text { Chinese hamster ovary } \\ \text { CPS } & \text { Capsular polysaccharide } \\ \text { FSC } & \text { Forward scatter } \\ \text { H\&E } & \text { Hematoxylin and eosin } \\ \text { HEK293-T } & \text { Human embryonic kidney 293-T } \\ \text { IP } & \text { Intraperitoneal } \\ \text { IPD } & \text { Invasive pneumococcal disease } \\ \text { IT } & \text { Intratracheal } \\ \text { IV } & \text { Intravenous } \\ \text { LDH } & \text { Lactate dehydrogenase } \\ \text { MTT } & \text { 3-(4,5-Dimethylthiazol-2-yl)-2, } \\ & \text { 5-diphenyltetrazolium bromide } \\ \text { OPA } & \text { Opsonophagocytosis assay } \\ \text { PI } & \text { Propidium iodide } \\ \text { Pn3P } & \text { Pneumococcal type 3 polysaccharide } \\ \text { Spn } & \text { Streptococcus pneumoniae } \\ \text { Spn3 } & \text { Streptococcus pneumoniae Serotype 3 } \\ \text { SSC } & \text { Side scatter } \\ \text { WT } & \text { Wild-type } \\ & \end{array}$

\section{INTRODUCTION}

Invasive pneumococcal diseases (IPD) caused by Spn have been a major threat to human health with alarming morbidity and mortality rates. According to $\mathrm{CDC}$ and WHO, in 2008 Spn 
infected approximately 150 million children and caused 1.6 million deaths worldwide (1). Additionally, pneumococcal coinfections are a driving force behind the mortality associated with other infectious diseases, such as influenza and the recent pandemic outbreak COVID-19 (2,3). In a recent study, about sixty percent of COVID-19 infected individuals were shown to be co-infected with $S$. pneumonia, the most frequent of all respiratory pathogens identified in these patients (4). Pneumococcal vaccines have been developed through conjugation of the pneumococcal capsular polysaccharide (CPS) with a carrier protein. While multivalent conjugate vaccines (including PCV7 and PCV13) have greatly reduced the overall incidence in broad pneumococcal infections (5-8), these vaccines have not solved a number of important issues with regards to Spn (9). Pneumococcal vaccines are variably/poorly immunogenic among young children, the elderly, and immunocompromised individuals. The mainstay of drug therapy for IPD is antibiotic treatment; however, widespread use of antibiotics against Spn has led to spread of drug resistant pneumococcal strains. In 2015, according to CDC, pneumococcal bacteria are resistant to one or more antibiotics in $30 \%$ of cases (10). While conjugate vaccines have been effective for preventing carriage and disease caused by most $S$. pneumoniae serotypes included in the vaccines, one major exception has been serotype 3. Pneumococcal type 3 polysaccharide $(\mathrm{Pn} 3 \mathrm{P})$ is one of the target components of the PCV13 conjugate vaccine $(11,12)$. However, numerous studies have shown serotype 3 is highly unresponsive to the current pneumococcal multi-valent conjugate vaccines (13-16), and incidence rates of serotype 3 continue to rise (17). Previous opsonophagocytosis assays (OPAs) show that significantly higher titers are required against Spn 3 compared to other target serotypes (18-20). While serotype 3 accounts for more than $10 \%$ (and increasing) of morbidity associated with IPD, it is responsible for approximately 25\% of sepsis caused by Spn and even more dramatically, IPD caused by serotype 3 has $30 \%$ higher mortality rate than other serotypes (21-23). Recent epidemiology work reveals serotype 3 as the most prevalent serotype identified in cases of community-acquired pneumonia, all of which required hospitalization (24). A recent report by Harvard School of Public Health, CDC and other US and international organizations has described the global emergence of serotype 3 strains with increasing genetic recombination rates and antibiotic resistance, highlighting the tremendous and increasing threat of this invasive serotype (25). The CDC predicts this antibiotic resistance of Spn3 to continue to rise $(26,27)$. Overcoming these hurdles in IPD treatment could thus greatly reduce both the morbidity and the mortality associated with Spn3 infection.

We have recently identified and cloned the Pn3Pase gene expressed by a Paenibacillus strain (28). The purified Pn3Pase enzyme degrades the CPS of Spn3 specifically, rendering the bacterium immune-susceptible. Capsular polysaccharide is the major virulence factor of Spn, and most unencapsulated bacteria are not infective $(29,30)$. We performed key proof-ofprinciple experiments demonstrating that the enzyme successfully degrades the CPS on the surface of the live bacterium (31); the bacterium is susceptible to phagocytosis in the presence of the enzyme; Pn3Pase limits nasopharyngeal colonization; and Pn3Pase protects mice from lethal challenge (32). Most recently, we have identified the enzyme's catalytic domains and active sites along with its mechanism of action (33). Here, we demonstrate that Pn3Pase effectively overcomes Spn3 challenge in mice without inducing autoimmune or other cytotoxic effects. Furthermore, high dosages of this enzyme do not cause tissue damage in mouse lung models, and immune populations are not significantly altered following administration. Our results indicate that therapeutic development of Pn3Pase for use against Spn3 can effectively overcome infection without negatively altering immune/inflammatory responses.

\section{MATERIALS AND METHODS}

\section{Production of Recombinant Pn3Pase}

WT recombinant Pn3Pase was produced as previously described (31). The coding region of Pbac_3331 (Pn3Pase) was amplified from Paencibacillus sp. 32,352 genomic DNA into pDONR221 using BP clonase reaction (Thermo Fisher Scientific). After transformation into $\mathrm{DH} 5 \alpha$ cells and DNA sequence confirmation, LR clonase reaction (Thermo Fisher Scientific) was performed to insert into pET-DEST42 destination vector for the expression of a carboxy-terminal $\mathrm{His}_{6}$-tagged fusion protein in $E$. coli BL21(DE3) cells.

\section{Purification of Active Enzyme}

Active Pn3Pase was purified as previously described (33). Breifly, BL21 cells transformed with pET-DEST42-Pn3Pase were grown in LB medium supplemented with $100 \mu \mathrm{g} / \mathrm{mL}$ ampicillin at $37^{\circ} \mathrm{C}$. Protein expression was induced by adding Isopropyl $\beta$-D-1-thiogalactopyranoside to a final concentration of $1 \mathrm{mM}$ and the cell culture was incubated for $24 \mathrm{~h}$ at $20^{\circ} \mathrm{C}$. Cells were lysed in phosphate-buffered saline (PBS, pH 7.2) with $10 \mu \mathrm{g} / \mathrm{mL}$ DNase using EmulsiFlex-C5 homogenizer (Avestin). Lysate was cleared by centrifugation and passed through a $0.45-\mu \mathrm{m}$ filter. Proteins were purified by $\mathrm{Ni}^{2+}-\mathrm{NTA}$ resin at $4^{\circ} \mathrm{C}$ and eluted with $300 \mathrm{mM}$ imidazole. Elution was run through FPLC Superdex 200 sizing column (GE LifeSciences). Protein concentration was determined using NanoDrop (Thermo Fisher Scientific) using extinction coefficients for Pn3Pase protein determined using ExPASy ProtParam tool (34). 


\section{Streptococcus Pneumoniae Type 3 (Spn3)}

Streptococcus pneumoniae type 3 (WU2 strain) was generously provided by Dr. Moon Nahm (University of Alabama at Birmingham). Cells were cultured aerobically without shaking at $37^{\circ} \mathbf{C}$ on tryptic soy agar with $5 \%$ sheep blood (TSAB) or in Todd-Hewitt broth plus $0.5 \%$ yeast extract (THY) (BD Biosciences).

\section{Mice}

For infection experiments, eight-week-old female BALB/c mice were obtained from Taconic Biosciences (Hudson, NY) and housed in the Central Animal Facility at the University of Georgia. For non-infection experiments, eight-week-old female BALB/c mice were obtained from Jackson Laboratories (Bar Harbor, ME) and housed in the Center for Molecular Medicine animal facility at the University of Georgia. Mice were kept in microisolator cages and handled under biosafety level 2 (BSL2) hoods.

For tissue processing and subsequent flow cytometry, mice were euthanized through carbon dioxide in accordance with IACUC guidelines. Spleens and lymph nodes were harvested. Cell suspensions were generated through mechanical tissue disruption and collagenase D digestion. Red blood cells were lysed, and samples were filtered through $60 \mu \mathrm{m}$ nylon filters to obtain single cell suspensions.

All mouse experiments were in compliance with the University of Georgia Institutional Animal Care and Use Committee under an approved animal use protocol. Our animal use protocol adheres to the principles outlined in U.S. Government Principles for the Utilization and Care of Vertebrate Animals Used in Testing, Research and Training, the Animal Welfare Act, the Guide for the Care and Use of Laboratory Animals, and the AVMA Guidelines for the Euthanasia of Animals.

\section{Intraperitoneal Spn3 Challenge}

Mid-log-phase WU2 cultures were washed with sterile PBS and suspended at a concentration of $5 \times 10^{3} \mathrm{CFU} / 100 \mu \mathrm{l}$. Groups of 4 unanesthetized 8-week-old female BALB/c mice were injected intraperitoneally (IP) with $5 \times 10^{3} \mathrm{CFU}$. Control mice were injected intravenously with $5 \mu \mathrm{g}$ of heatinactivated Pn3Pase in $100 \mu \mathrm{l}$ of PBS directly after infection (Time 0). Treated mice were administered intravenously with $5 \mu \mathrm{g}$ of Pn3Pase in $100 \mu \mathrm{l}$ PBS at the time of infection. Animals were monitored every $12 \mathrm{~h}$ and survival was recorded.

\section{Intratracheal Spn3 Challenge and BAL}

Mid-log-phase WU2 cultures were washed with sterile PBS and suspended at a concentration of $10^{8} \mathrm{CFU} / 10 \mu \mathrm{l}$. Mice were anesthetized with a mixture of ketamine-acepromazinexylazine IP. A gel loading tip was then used to administer WU2 cell suspensions intratracheally (IT). Mice were then administered either $50 \mu \mathrm{g}$ of active or inactive Pn3Pase in $100 \mu \mathrm{l}$ PBS. After two days, mice were euthanized and bronchoalveolar lavages (BAL) were obtained by flushing out the lungs with PBS by insertion of a 25-gauge sheathed needle into the trachea. Serial dilutions of the nasal lavage fluid were plated on TSAB plates to enumerate the CFU.

\section{ELISA}

Mice were bled from the tail vein 14 days after initial injection of Pn3Pase (active or inactive, or SPN-challenged with active treatment). Pn3Pase-specific antibodies in serum were detected by ELISA in 96 well plates coated with $2 \mu \mathrm{g} / \mathrm{ml}$ of Pn3Pase for $24 \mathrm{~h}$. Four immune sera per group were used in all ELISA experiments. Anti-IgG-AP (Southern BioTech 1030-04), anti-IgM-AP (Southern BioTech 1020-04), and anti-IgA-AP (Southern BioTech 1040-04) were used to detect antibodies. Absorbance was measured at $405 \mathrm{~nm}$.

\section{Flow Cytometry}

Cells were stained in PBS with TruStain fcX (BioLegend, Cat. No. 101320) to reduce non-specific antibody binding. Cell samples were then stained with the following antibodies and stains (in multiple sets to prevent fluorophore overlap): B220FITC (BioLegend 103,206), CD4-PE (BioLegend 200,507), CD8-PECy5 (BioLegend 100,709), CD3-APC (BioLegend 100,311), F480-PEGy5 (BioLegend 123,111), CD45APCGy7 (BioLegend 103,115), CD19-PE (BioLegend 115,507), CD11c-PECy7(BioLegend 117,317), Ghost Red 710 (Tonbo 13-0871-T100), Annexin V-APG (BioLegend 640,919), and propidium iodide (BioLegend 421,301). Samples were washed and analyzed with flow cytometry (Beckman Coulter CytoFLEX). Isotype control antibodystained samples were used as negative staining controls where appropriate. Flow cytometry data was analyzed using FlowJo Single Cell Analysis Software (Treestar, Inc., Ashland, Oregon) with gating strategies shown in Fig. 4b.

\section{Mammalian Cell Lines}

CHO (Chinese Hamster Ovarian) and HEK293-T (human embryonic kidney) adherent cells were cultured in RPMl 1640 supplemented with $10 \%$ heat-inactivated FBS, $100 \mathrm{U} / \mathrm{ml}$ penicillin, $100 \mathrm{mg} / \mathrm{ml}$ streptomycin, 1\% (v/v) MEM non-essential amino acids, $1 \mathrm{mM}$ sodium pyruvate, 2 mM L-glutamine (Thermo Fisher Scientific), and $50 \mu \mathrm{M} \beta$-mercaptoethanol (Gibco). Cells were maintained at 5\% CO2 in filtered flasks at approximately $50 \%$ confluency. 


\section{LDH Cytotoxicity Assay}

CHO and HEK293-T cells were cultured in 96-well cell culture plates at $2 \times 10^{4}$ cells $/ 100 \mu \mathrm{L} /$ well. Active Pn3Pase was then added to cultured wells at serial dilutions in triplicate wells. After $24 \mathrm{~h}$ in cell culture (37C, $5 \% \mathrm{CO} 2)$, cytotoxicity was assessed using the Pierce LDH Cytotoxicity Assay Kit (Thermo Scientific, Rockford, IL) according to the manufacturer's instructions. PBS-treated samples were used as no cytotoxicity controls. 10X lysis-buffer-treated cells were used as maximum LDH activity control according to the manufacturer's recommendations.

\section{MTT Cell Viability Assay}

CHO and HEK293-T cells were cultured in 96-well cell culture plates at $2 \times 10^{4}$ cells $/ 100 \mu \mathrm{L} /$ well in triplicate. Active Pn3Pase was then added to cultured wells at serial dilutions. After $48 \mathrm{~h}$ in cell culture $\left(37^{\circ} \mathrm{C}, 5 \% \mathrm{CO}_{2}\right)$, cell viability was assessed using the MTT cell proliferation assay kit (Cayman Chemical, Ann Arbor, MI) according to the manufacturer's instructions. Absorbance was measured at $570 \mathrm{~nm}$. PBStreated samples were used as $100 \%$ cell viability controls.

\section{H\&E Staining}

$50 \mu \mathrm{g} / 100 \mu \mathrm{L}$ Pn3Pase or PBS was administered through the tail vein of BALB/c mice $(n=4)$. Mice were euthanized and lungs were harvested and fixed in $2 \%$ paraformaldehyde for $48 \mathrm{~h}$. Lung tissues were then washed with $70 \%$ ethanol for sectioning. Tissues were embedded, processed, and stained with $\mathrm{H} \& \mathrm{E}$ through the Medical College of Georgia Electron Microscopy and Histology Core at Augusta University. Images were obtained using the Lionheart FX Automated Microscope (BioTek).

\section{Statistical Analysis}

GraphPad Prism v8 was used for statistical analyses. Where appropriate one-way ANOVA with multiple comparisons tests was used to determine statistical significance between experimental groups in each of the applicable experimental models.

\section{RESULTS}

\section{Pn3Pase Induces Minimal Cytotoxic Response In Vivo}

After observing the efficacy of this enzyme when used therapeutically through intraperitoneal administration (32), we aimed to determine its effects on lung tissue as the ultimate target of the enzyme will be respiratory infections of Spn3. We therefore injected BALB/c mice with high doses $(50 \mu \mathrm{g} / \mathrm{mouse})$ intravenously at different timepoints (8 days, 4 days, 2 days, and 1 day before sacrifice) to determine if any lung inflammation can be observed following abovetherapeutic administration. Hematoxylin and eosin $(\mathrm{H} \& \mathrm{E})$ staining followed by microscopy was used to observe structure of the lungs after administration (Fig. 1). No lung inflammation was observed at any timepoint compared to mice that received no injection of Pn3Pase, indicating that even a dose ten times higher than previously used therapeutically does not induce lung tissue damage in mice.

\section{Pn3Pase Remains Active for Therapeutic Periods in a Respiratory Mouse Model}

We previously reported that Pn3Pase effectively overcomes systemic Spn3 lethal challenge in an intraperitoneal mouse model of infection (32). To specifically assess the enzyme's therapeutic activity in an upper respiratory infection model, mice were challenged with Spn3 through intratracheal administration of the bacterial suspension. Active or heat-inactivated Pn3Pase was then administered intravenously through the tail vain. After two days, all mice were euthanized, and BAL lavage followed by plating was used to count colony forming units (CFUs) within the lungs of each group. Mice that received inactivated Pn3Pase showed significantly higher Spn3 CFUs compared to mice that received therapeutic concentration of active Pn3Pase (Fig. 2a), indicating the efficacy of this enzyme in upper respiratory infection.

\section{Prior Administration of Pn3Pase Does Not Prevent Enzyme Efficacy Following Bacterial Challenge}

One concern in developing Pn3Pase as a therapeutic for use in Spn3 infections is how repeated administrations could generate an immune response against the enzyme itself, leading to loss of efficacy following immune cell targeting and degradation of the enzyme, and/or an allergic response indicated by inflammatory factors. To test the efficacy of this enzyme in a repeat administration experiment, we first injected mice intravenously with either active or inactive Pn3Pase. After fourteen days, mice were lethally challenged with Spn3 intraperitoneally. Inactive enzyme was used as a control against possible immune response generated against the protein structure and to demonstrate the specific requirement for enzyme activity of Pn3Pase in this infection model. Active or inactive enzyme was then administered to the groups and survival was monitored. Initial administration before challenge had no apparent effect on mouse survival as only mice that received a postchallenge injection of active enzyme exhibited high survival rates after two days (Fig. 2b). A pre-challenge injection of active Pn3Pase did not prevent effective mouse response to the Spn3 when active Pn3Pase was used as a treatment. This 
Fig. I Tissue structure maintained after high dose of active Pn3Pase. BALB/C mice ( $n=4$ /timepoint) were injected with $50 \mu \mathrm{g} / \mathrm{l} 00 \mu \mathrm{l} /$ mouse

intravenously through the tail vein at $192 \mathrm{~h}, 96 \mathrm{~h}, 48 \mathrm{~h}$, and $24 \mathrm{~h}$ before sacrifice. Mice that received no enzyme were used as a control group. Lungs were harvested and fixed in $4 \%$ paraformaldehyde for $48 \mathrm{~h}$. Lungs were then washed with $70 \%$ ethanol and embedded in paraffin for sectioning and H\&E staining. Shown are representative H\&E lung stains for each timepoint at low, medium, and high magnifications (left to right).
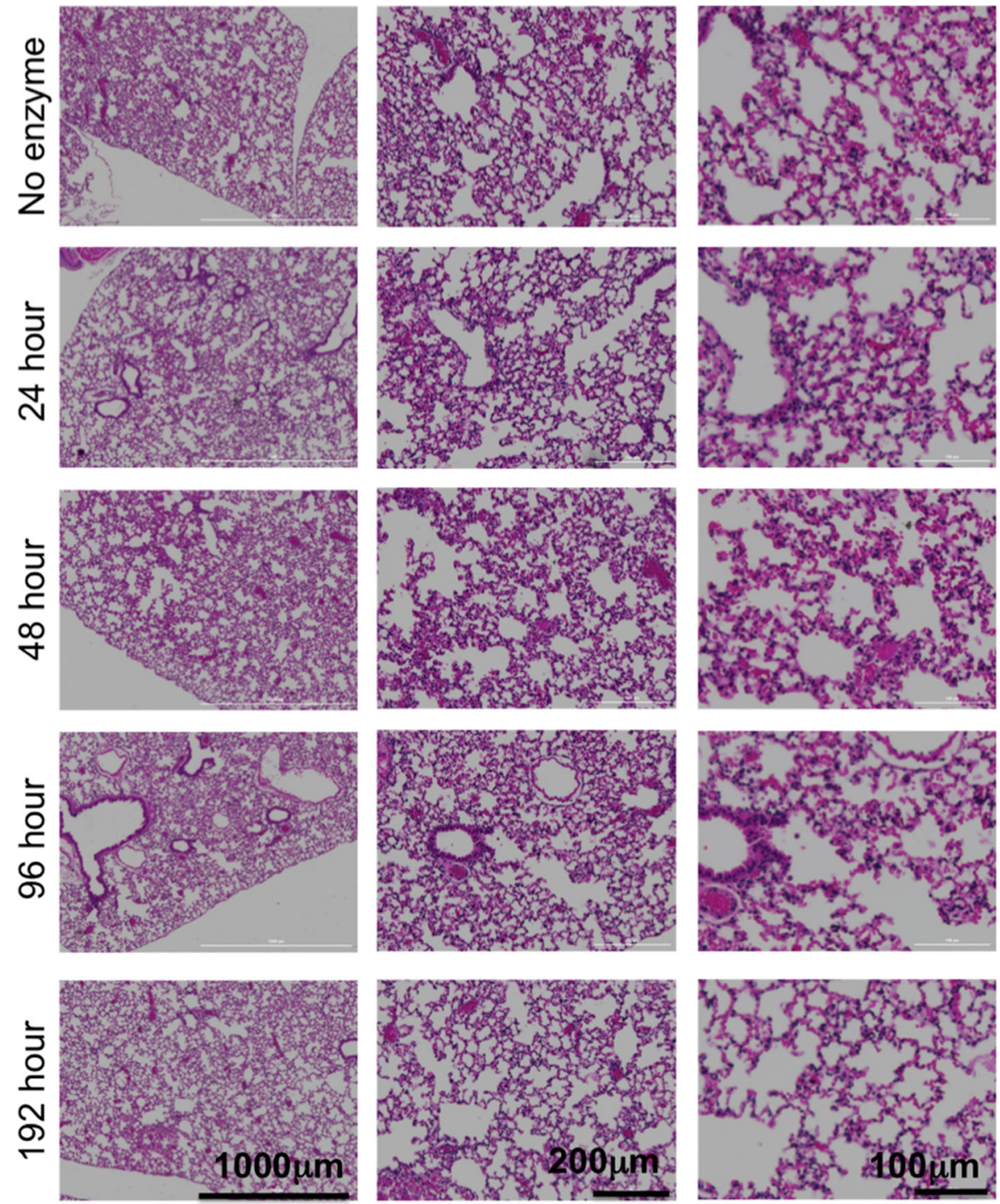

a Intratracheal Challenge

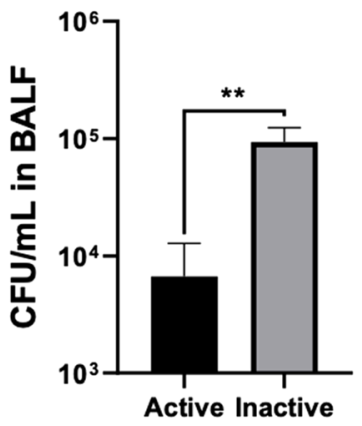

b Intraperitoneal Challenge

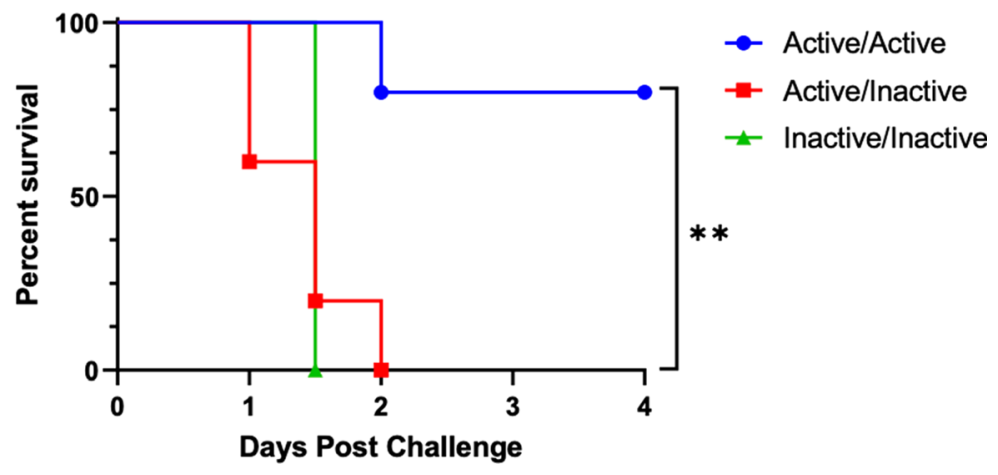

Fig. 2 In vivo efficacy of Pn3pase. (a) Spn3 was administered to mice intratracheally. Mice were then treated with active $(n=4)$ or inactive $(n=3)$ Pn3Pase. Two days after infection, mice were euthanized, and BAL lavage was used to obtain lung colonies. Lavage samples were plated overnight and CFUs were assessed. $p=0.0023$. (b) Active or inactive Pn3Pase was administered to mice $(n=5)$ intravenously. After 14 days, mice were challenged with Spn3 intraperitoneally and treated with active or inactive enzyme as indicated. Mouse survival was monitored and recorded. Long-rank (Mantel-Cox) test, $p=0.0037$. 
indicates that repeated administration of Pn3Pase retains efficacy against the bacteria.

\section{Pn3Pase Does Not Induce Significant Titer Response Following High-Dose Administration}

To determine if high dosages of Pn3Pase can induce antibody responses against the enzyme, mice were injected with $50 \mu \mathrm{g}$ active or inactive Pn3Pase (to exceed therapeutic conditions of $5 \mu \mathrm{g}$ ) with or without concurrent Spn3 challenge. After 14 days, serum was collected, and ELISA was performed using active Pn3Pase-coated ELISA plates to analyze titer responses. At high serum concentrations (1:200), no significant differences in IgG, IgM, or IgA levels were observed between any groups (Fig. 3). Antibody response against the active enzyme is therefore minimal and not indicative of an immune response.

\section{Pn3Pase Induces Minimal Cytotoxic Response In Vitro}

After confirming that Pn3Pase administration does not significantly induce antibody responses, we next determined whether high dosage could disrupt immune cell homeostasis in vitro. We first harvested spleen and lymph nodes from healthy wildtype BABL/c mice $(n=3)$. Single cell suspensions were generated, and red blood cells were lysed. Concurrently, cell suspension was also prepared of $4 \mathrm{~T}-1$ murine breast cancer cell lines. Tumor cells, splenocytes and lymphocytes were plated with or without high concentrations of active Pn3Pase. After six hours, flow cytometry was used to determine apoptotic cell populations in each group. High dosage of Pn3Pase did not significantly increase or decrease the percent of apoptotic $(\mathrm{AV}+\mathrm{PI}+)$ immune-gated cells (Fig. 4a). To confirm these findings in vivo, healthy WT BALB/c mice were intravenously administered $50 \mu \mathrm{g}$ active Pn3Pase versus PBS control. After 7 days, spleens and lymph nodes were harvested, and single cell suspensions were generated. Common immune cell markers were analyzed through cell surface staining and flow cytometry, as well as propidium iodide staining to account for cellular apoptosis (Fig. 4b). No significant changes in the active enzyme treatment group compared to control, nor changes in $\mathrm{AV}^{+}$or $\mathrm{PI}^{+}$cells were observed, indicating no disruption of immune cell homeostasis at the most fundamental levels following administration of Pn3Pase.

\section{Pn3Pase Induces Minimal Cytotoxic Response In Vitro}

While these results were highly promising for the potential of Pn3Pase as a therapeutic we next sought to confirm that it does not inhibit cellular proliferation or has no cytotoxic effects. To that end, Chinese Hamster Ovary (CHO) and human embryonic kidney (HEK293-T) adherent cell lines were cultured in a MTT with serial dilutions of Pn3Pase to determine its effects on cell proliferation. Even at high concentrations, the enzyme-treated cells showed no significant decrease in cell proliferation compared to control (Fig. 5a-b). Additionally, when these concentrations of Pn3Pase were tested in an LDH cytotoxicity assay, the highest concentration of Pn3Pase $(100 \mu \mathrm{g} / \mathrm{mL})$ showed approximately $3 \%$ cytotoxicity compared to the positive control (Fig. 5c-d). Taken together, this data indicates that upwards of $50 \mathrm{X}$ higher than therapeutic concentrations of Pn3Pase can be administered with no significant effects on mammalian cell viability.

\section{DISCUSSION}

The unique mucinous CPS composition $(18,35,36)$ of Spn3 can effectively shield the bacterium from immune mechanisms such as opsonophagocytosis in addition to providing other virulence mechanisms such as adherence (29,37). Removing the capsule either through genetic mutation or enzyme treatment can overcome this resistance to host defense mechanisms (29,38). Targeting the bacterium through removal of its CPS would therefore be a promising strategy to overcome Spn3 resistance to immune-mediated clearance. We have
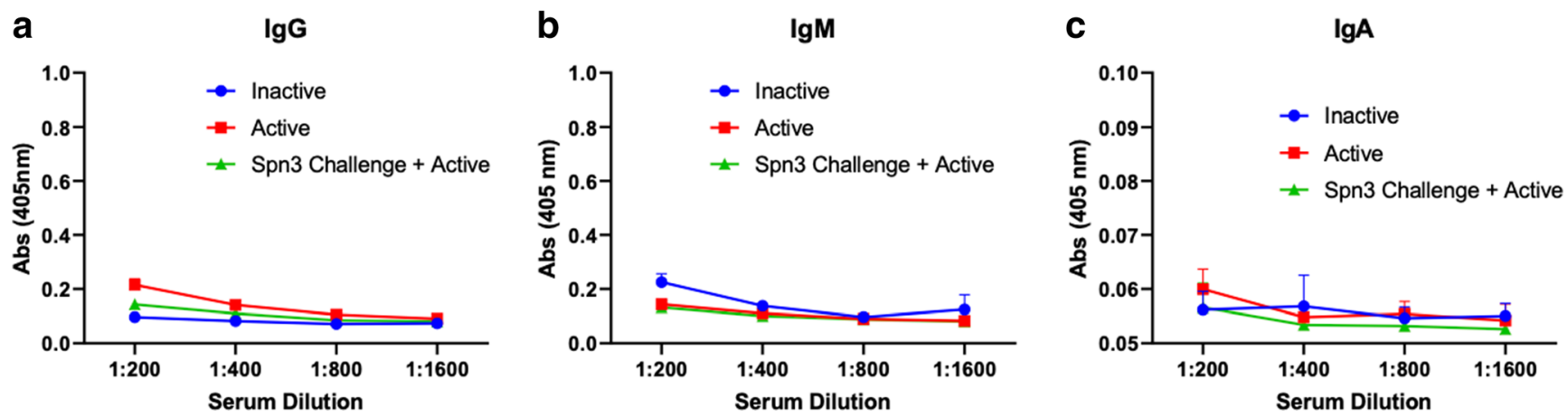

Fig. 3 Minimal antibody response against Pn3pase in vivo mouse model. Active or heat inactivated Pn3Pase $(50 \mu \mathrm{g} / \mathrm{I} 00 \mu \mathrm{l})$ was injected intravenously into mice with or without concurrent Spn3 intraperitoneal challenge. After 14 days, serum was collected, and ELISA was performed to test serum (at indicated dilutions) $\lg G(\mathbf{a})$, IgM (b), or IgA (c) responses against active Pn3Pase. No significant differences between enzyme-treated groups were observed at different dilutions using obtained using ordinary ANOVA. 
a

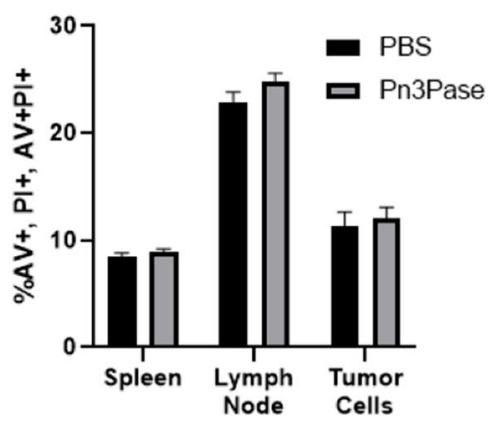

b

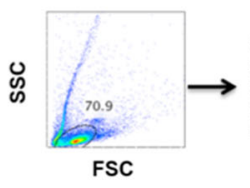

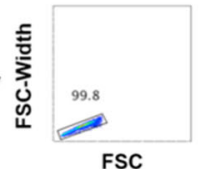
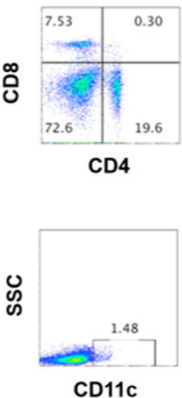

FSC

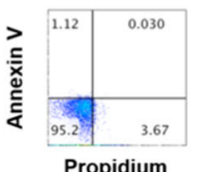

Propidium

$\downarrow$
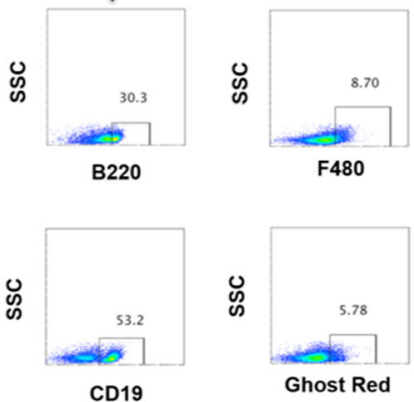

ymph Node

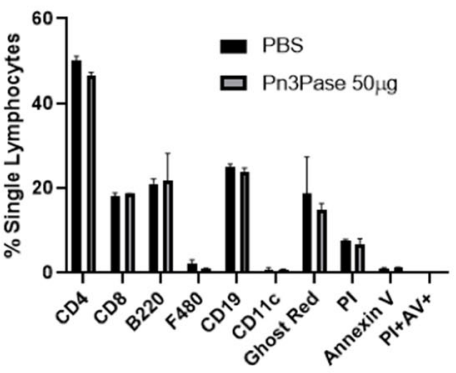

Spleen (Total)

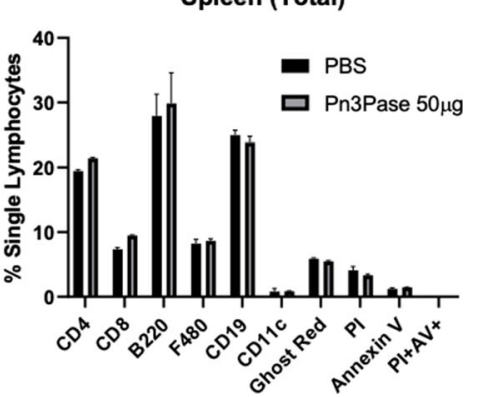

Fig. 4 Assessment of cellular cytotoxicity following Pn3Pase treatment of mouse cells. (a) Spleens, lymph nodes were obtained from healthy $\mathrm{BALB} / \mathrm{c}$ mice and single cell suspensions were generated. Murine breast tumor cell line $4 \mathrm{~T}$ - I was also prepared in single cell suspensions. Cells were plated in 96well plates with or without $10 \mu \mathrm{g} / \mu \mathrm{L} \mathrm{Pn3Pase}$ for six hours. Cells were then analyzed for annexin $V$ cell surface expression and propidium iodide permeability using flow cytometry. No data points showed significant statistical differences between PBS and Pn3Pase-treated based on ordinary One Way ANOVA. (b) BALB/c mice ( $n=3$, age 8 weeks) were treated with or without $50 \mu \mathrm{g} /$ mouse active Pn3pase intravenously. After 7 days, mice were euthanized, and lymph nodes and spleens were harvested and digested into single-cell suspensions. Tissue samples were stained with indicated conjugated fluorescent antibodies (BioLegend) and analyzed using flow cytometry (Beckman Coulter Cytoflex). Single cells were gated based on FSC and SSC as indicated. No data points showed significant statistical differences between PBS and Pn3Pase-treated based on ordinary One Way ANOVA.

investigated Pn3Pase as an enzyme therapy to sensitize Spn3 to immune killing mechanisms such as opsonophagocytosis (32), thereby reducing bacterial colonization and infection in mouse models $(32,33)$.

Here, we show that doses of enzyme that significantly exceed established therapeutically efficacious concentrations can be administered without inducing significant $\operatorname{IgG}$, IgM, or IgA titer responses against the enzyme up to 14 days after administration, though extended timepoints following administration remain to be assessed as the mice may potentially develop antibodies later. Additionally, prior administration of the enzyme before lethal bacterial challenge and subsequent treatment does
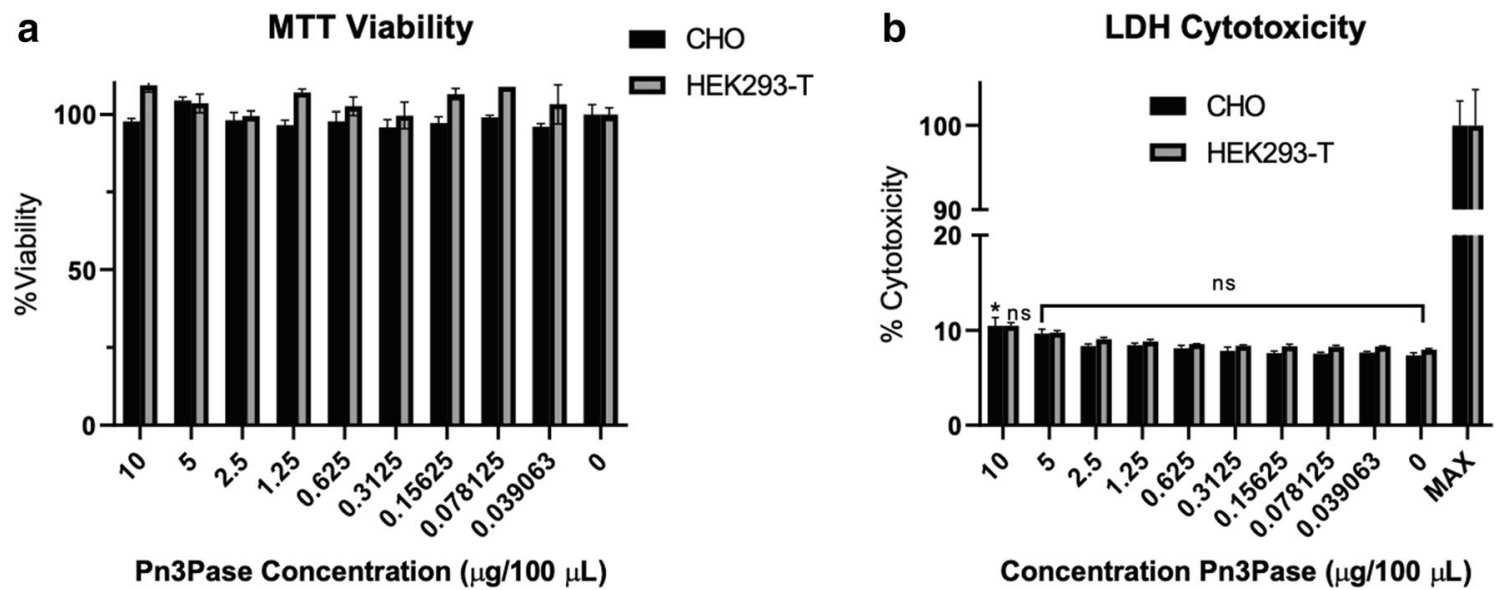

Fig. 5 Assessment of cellular cytotoxicity in cell lines. $\mathrm{CHO}$ and HEK293-T cells were seeded in 96 -well plates at $2 \times 10^{4}$ cells/I00 $\mu \mathrm{L} /$ well. Active Pn3pase was added at the indicated concentrations. (a) MTT metabolism was measured after $48 \mathrm{~h}$ according to the manufacturer's protocol to assess cellular proliferation using spectrophotometry and quantified. \% Viability was determined as changes relative to no treatment control group. Two-way ANOVA with Tukey's Multiple Comparison's test was used to compare groups to no treatment, and no significant differences were observed. (b) LDH secretion was measured after $48 \mathrm{~h}$ to assess cellular cytotoxicity using spectrophotometry and quantified. \% Cytotoxicity was determined relative to MAX levels as observed after cell lysis. Two-way ANOVA with Dunnett's multiple comparisons test was used to compare readouts to untreated control samples. 
not inhibit its effective rescue of mice. Immune populations remain unchanged following high Pn3Pase dosage, which does not alter cell viability or induce cell death, either in vitro or in viwo.

Multiple unmet needs must be addressed in overcoming the hurdles of Spn3 treatment. We have shown that this has great potential to serve as an effective alternative to antibiotics and can minimize antibiotic resistance through specific removal of the CPS without the need for administration of broad-spectrum antibiotics. Furthermore, as broad-spectrum antibiotics have also been linked with disruption of vital commensal bacterial populations (39-41), the demand for strainspecific treatments has arisen as an alternative to reduce offtarget effects. We have shown that Pn3Pase is specific to Spn3 and therefore circumvents the problem of non-specific resident bacterial population dysregulation. Our method of enzyme administration to promote anti-Spn immunity therefore represents a viable alternative approach to overcome Spn3 persistence and mortality. Information from this current study will aid in further developing Pn3Pase as an alternative to conventional treatments such as antibiotics, establishing the biochemical characteristics necessary for optimum therapeutic potential.

Another major hurdle in treatment of Spn in general and especially type 3 is its virulence in immunocompromised individuals. As one significant shortcoming of vaccine therapy is reduced efficacy in key high-risk populations, including elderly and otherwise immunocompromised patients $(42,43)$, enzyme therapy could present a competitive advantage.

\section{CONCLUSIONS}

Current clinical research has shown that, thanks to more advanced techniques for quickly and more accurately assessing serotypes in patients, incidence rates for Spn3 are actually much higher than had previously been assumed $(15,24)$. These demonstrated incidence rates indicate a developing need for additional therapeutic options targeting Spn3. This study showing no effects on mammalian lung structure or immune repertoires in Pn3Pase-treated animal models, together with our previous research showing the efficacy of the enzyme against Spn3 lethality, indicate this enzyme's potential in moving towards clinical use.

\section{ACKNOWLEDGMENTS AND DISCLOSURES}

We would like to thank Liang Zhang for assistance with Lionheart microscopy. We would also like to thank Donna Kumiski and the EM/Histology Core Laboratory at Augusta University for assistance with H\&E staining. This work was supported by National Institutes of Health grant
R01AI123383 (FA) and Georgia Research Alliance Venture Fund (FA, AP).

\section{REFERENCES}

1. WHO position paper. Pneumococcal conjugate vaccine for childhood immunization. Wkly Epidemiol Rec. 2007;82(12):93-104.

2. Rynda-Apple A, Robinson KM, Alcorn JF. Influenza and bacterial superinfection: illuminating the immunologic mechanisms of disease. Infect Immun. 2015;83(10):3764-70.

3. Smith AM, Adler FR, Ribeiro RM, Gutenkunst RN, McAuley JL, McCullers JA, et al. Kinetics of coinfection with influenza A virus and Streptococcus pneumoniae. PLoSPathog. 2013;9(3):e1003238.

4. Zhu X, Ge Y, Wu T, Zhao K, Chen Y, Wu B, et al. Co-infection with respiratory pathogens among COVID-2019 cases. Virus Res. 2020;285:198005.

5. Wantuch PL, Avci FY. Invasive pneumococcal disease in relation to vaccine type serotypes. Hum Vaccin Immunother. 2019;15(4):874875.

6. Tin TinHtar M, Stuurman AL, Ferreira G, Alicino C, Bollaerts K, Paganino C, et al. Effectiveness of pneumococcal vaccines in preventing pneumonia in adults, a systematic review and metaanalyses of observational studies. PLoS One. 2017;12(5):e0177985.

7. Harboe ZB, Dalby T, Weinberger DM, Benfield T, Molbak K, Slotved HC, et al. Impact of 13-valent pneumococcal conjugate vaccination in invasive pneumococcal disease incidence and mortality. Clin Infect Dis. 2014;59(8):1066-73.

8. Bonten MJ, Huijts SM, Bolkenbaas M, Webber C, Patterson S, Gault $\mathrm{S}$, et al. Polysaccharide conjugate vaccine against pneumococcal pneumonia in adults. N Engl J Med. 2015;372(12):1114-25.

9. Avci F, Berti F, Dull P, Hennessey J, Pavliak V, Prasad AK, et al. Glycoconjugates: What it would take to master these well-known yet little-understood immunogens for vaccine development. mSphere. 2019;4(5):e00520-19.

10. Kim L, McGee L, Tomczyk S, Beall B. Biological and epidemiological features of antibiotic-resistant Streptococcus pneumoniae in pre- and post-conjugate vaccine eras: a United States perspective. ClinMicrobiol Rev. 2016;29(3):525-52.

11. Dagan R, Patterson S, Juergens C, Greenberg D, Givon-Lavi N, Porat N, et al. Comparative immunogenicity and efficacy of 13valent and 7 -valent pneumococcal conjugate vaccines in reducing nasopharyngeal colonization: a randomized double-blind trial. Clin Infect Dis. 2013;57(7):952-62.

12. Richter SS, Heilmann KP, Dohrn GL, Riahi F, Diekema DJ, Doern GV. Pneumococcal serotypes before and after introduction of conjugate vaccines, United States, 1999-2011(1.). Emerg Infect Dis. 2013;19(7):1074-83.

13. Linley E, Bell A, Gritzfeld JF, Borrow R. Should pneumococcal serotype 3 be included in serotype-specific immunoassays? Vaccines (Basel). 2019;7(1):4.

14. Silva-Costa C, Brito MJ, Pinho MD, Friaes A, Aguiar SI, Ramirez $\mathrm{M}$, et al. Pediatric complicated pneumonia caused by Streptococcus pneumoniae serotype 3 in 13-valent pneumococcal conjugate vaccinees, Portugal, 2010-2015. Emerg Infect Dis. 2018;24(7): 1307-14.

15. Horacio AN, Silva-Costa C, Lopes JP, Ramirez M, Melo-Cristino J, Portuguese Group for the Study of Streptococcal I. Serotype 3 remains the leading cause of invasive pneumococcal disease in adults in Portugal (2012-2014) despite continued reductions in other 13-valent conjugate vaccine serotypes. Front Microbiol. 2016;7: 1616.

16. Horacio AN, Lopes JP, Ramirez M, Melo-Cristino J, Portuguese Group for the Study of Streptococcal I. Non-invasive 
pneumococcal pneumonia in Portugal-serotype distribution and antimicrobial resistance. PLoS One. 2014;9(7):e103092.

17. Wijayasri S, Hillier K, Lim GH, Harris TM, Wilson SE, Deeks SL. The shifting epidemiology and serotype distribution of invasive pneumococcal disease in Ontario, Canada, 2007-2017. PLoS ONE. 2019;14(12):e0226353.

18. Geno KA, Gilbert GL, Song JY, Skovsted IC, Klugman KP, Jones C, et al. Pneumococcal capsules and their types: past, present, and future. ClinMicrobiol Rev. 2015;28(3):871-99.

19. Jackson LA, El Sahly HM, George S, Winokur P, Edwards K, Brady RC, et al. Randomized clinical trial of a single versus a double dose of 13-valent pneumococcal conjugate vaccine in adults 55 through 74 years of age previously vaccinated with 23-valent pneumococcal polysaccharide vaccine. Vaccine. 2018;36(5):606-14.

20. Kieninger DM, Kueper K, Steul K, Juergens C, Ahlers N, Baker S, et al. Safety, tolerability, and immunologic noninferiority of a 13valent pneumococcal conjugate vaccine compared to a 7 -valent pneumococcal conjugate vaccine given with routine pediatric vaccinations in Germany. Vaccine. 2010;28(25):4192-203.

21. Martens P, Worm SW, Lundgren B, Konradsen HB, Benfield T. Serotype-specific mortality from invasive Streptococcus pneumoniae disease revisited. BMC Infect Dis. 2004;4:21.

22. Briles DE, Crain MJ, Gray BM, Forman C, Yother J. Strong association between capsular type and virulence for mice among human isolates of Streptococcus pneumoniae. Infect Immun. 1992;60(1): $111-6$.

23. Weinberger DM, Harboe ZB, Sanders EA, Ndiritu M, Klugman $\mathrm{KP}$, Ruckinger S, et al. Association of serotype with risk of death due to pneumococcal pneumonia: a meta-analysis. Clin Infect Dis. 2010;51(6):692-9

24. Forstner G, Kolditz M, Kesselmeier M, Ewig S, Rohde G, BartenNeiner $\mathrm{G}$, et al. Pneumococcal conjugate serotype distribution and predominating role of serotype 3 in German adults with community-acquired pneumonia. Vaccine. 2020;38(5):1129-36.

25. Azarian T, Mitchell PK, Georgieva M, Thompson CM, Ghouila A, Pollard AJ, et al. Global emergence and population dynamics of divergent serotype 3 GC180 pneumococci. PLoSPathog. 2018;14(11):e1007438.

26. Metcalf BJ, Gertz RE, Jr., Gladstone RA, Walker H, Sherwood LK, Jackson D, et al. Strain features and distributions in pneumococci from children with invasive disease before and after 13-valent conjugate vaccine implementation in the USA. Clin Microbiol Infect. 2016;22(1):60 e9-e29.

27. Li Y, Metcalf BJ, Chochua S, Li Z, Gertz RE, Jr., Walker H, et al. Penicillin-binding protein transpeptidase signatures for tracking and predicting beta-lactam resistance levels in streptococcus pneumoniae. mBio. 2016;7(3):e00756-16.

28. Middleton DR, Lorenz W, Avci FY. Complete genome sequence of the bacterium bacillus circulans jordan strain 32352. Genome Announc. 2017;5(19):e00289-17.

29. Magee AD, Yother J. Requirement for capsule in colonization by Streptococcus pneumoniae. Infect Immun. 2001;69(6):3755-61.
30. Kadioglu A, Weiser JN, Paton JC, Andrew PW. The role of Streptococcus pneumoniae virulence factors in host respiratory colonization and disease. Nat Rev Microbiol. 2008;6(4):288-301.

31. Middleton DR, Zhang X, Wantuch PL, Ozdilek A, Liu X, LoPilato $\mathrm{R}$, et al. Identification and characterization of the Streptococcus pneumoniae type 3 capsule-specific glycoside hydrolase of Paenibacillus species 32352. Glycobiology. 2018;28(2):90-9.

32. Middleton DR, Paschall AV, Duke JA, Avci FY. Enzymatic hydrolysis of pneumococcal capsular polysaccharide renders the bacterium vulnerable to host defense. Infect Immun. 2018;86(8):e0031618.

33. Wantuch PL, Jella S, Duke JA, Mousa JJ, Henrissat B, Glushka J, et al. Characterization of the beta-glucuronidase Pn3Pase as the founding member of glycoside hydrolase family GH169. Glycobiology. 2020. https://doi.org/10.1093/glycob/cwaa070.

34. Gasteiger E, Gattiker A, Hoogland C, Ivanyi I, Appel RD, Bairoch A. ExPASy: the proteomics server for in-depth protein knowledge and analysis. Nucleic Acids Res. 2003;31(13):3784-8.

35. Choi EH, Zhang F, Lu YJ, Malley R. Capsular polysaccharide (CPS) release by Serotype 3 pneumococcal strains reduces the protective effect of anti-type 3 CPS antibodies. Clin Vaccine Immunol. 2016;23(2):162-7.

36. Sugimoto N, Yamagishi Y, Hirai J, Sakanashi D, Suematsu H, Nishiyama $\mathrm{N}$, et al. Invasive pneumococcal disease caused by mucoid serotype 3 Streptococcus pneumoniae: a case report and literature review. BMC Res Notes. 2017;10(1):21.

37. Moxon ER, Kroll JS. The role of bacterial polysaccharide capsules as virulence factors. Curr Top MicrobiolImmunol. 1990;150:6585.

38. Nelson AL, Roche AM, Gould JM, Chim K, Ratner AJ, Weiser JN. Capsule enhances pneumococcal colonization by limiting mucusmediated clearance. Infect Immun. 2007;75(1):83-90.

39. Langdon A, Crook N, Dantas G. The effects of antibiotics on the microbiome throughout development and alternative approaches for therapeutic modulation. Genome Med. 2016;8(1):39.

40. Becattini S, Taur Y, Pamer EG. Antibiotic-induced changes in the intestinal microbiota and disease. Trends Mol Med. 2016;22(6): 458-78.

41. Croswell A, Amir E, Teggatz P, Barman M, Salzman NH. Prolonged impact of antibiotics on intestinal microbial ecology and susceptibility to enteric Salmonella infection. Infect Immun. 2009;77(7):2741-53.

42. Shapiro ED, Berg AT, Austrian R, Schroeder D, Parcells V, Margolis A, et al. The protective efficacy of polyvalent pneumococcal polysaccharide vaccine. N Engl J Med. 1991;325(21):1453-60.

43. Berical AC, Harris D, Dela Cruz CS, Possick JD. Pneumococcal vaccination strategies. An update and perspective. Ann Am ThoracSoc. 2016;13(6):933-44.

Publisher's Note Springer Nature remains neutral with regard to jurisdictional claims in published maps and institutional affliations. 